\title{
Trends and Challenges in the Industrialization of Natural Colorants
}

\author{
Maria Isabel Landim Neves, Eric Keven Silva, M. Angela A. Meireles* \\ LASEFI/DEA/FEA (School of Food Engineering), UNICAMP (University of Campinas), Campinas, SP, Brazil
}

\begin{abstract}
Consumer demands and their preferences for naturally derived colorants have increased exponentially and are widely associated with the image of healthy, safe and high-quality products, which constitutes a great challenge to food industries and related food science research institutions. Moreover, such demands have resulted in searches to increase the availability of these compounds. Despite the intense search for plant and microbial sources and efforts to increase extraction yield, few natural colorants have reached available the market. Physicochemical instability during the extraction and storage of natural colorants is a major limitation; some non-conventional extraction and encapsulation technologies are being advocated to minimize this problem. Thus, improving the techniques used for the encapsulation of sensitive or labile ingredients is important to make colorants and, consequently, their bioactive proprieties, accessible to consumers.
\end{abstract}

Keywords Nonconventional extraction, Encapsulation, Precipitation, Supercritical fluids

\section{Introduction}

Color additives can be natural or synthetic [1] and have a function to impart, restore, or standardize the color of food, making them sensorially more attractive to consumers. The production of synthetic colorants is less expensive than natural colors, and they have higher chemical stability without conveying flavor to products [2, 3]. However, one of the limiting factors associated with using synthetic colorants is their potential effects on human health, depending on the dose that is used. In addition to regulations, consumers also show a higher preference for food products that use natural ingredients [4]. These circumstances have strongly influenced the food sector, which emphasis on replacing the synthetic colorants with natural colorants in food products.

Currently, the production of natural colorants has tended to grow worldwide. It is expected that the global market will grow at an annual rate of $6.22 \%$ over the period $2015-2019$ [5]. Commonly used natural food pigments include anthocyanins, carotenoids, betalains, and chlorophylls, among others $[1,5]$.

Natural food colorants have received particular attention, not only because they are potent substitutes for synthetic additives but also because they provide health and security benefits to consumers [2] such as their anti-inflammatory,

* Corresponding author:

maameireles@lasefi.com (M. Angela A. Meireles)

Published online at http://journal.sapub.org/fph

Copyright (C) 2019 The Author(s). Published by Scientific \& Academic Publishing

This work is licensed under the Creative Commons Attribution International

License (CC BY). http://creativecommons.org/licenses/by/4.0/ antimicrobial, anti-amyloid, and antitumor proprieties. Additionally, these compounds have been associated with reductions in several diseases, such as diabetes and obesity $[5]$.

A challenge for the industry is to keep these natural bioactive products available and stable until reaching the final consumer, ultimately to promote benefits to human health $[2,6]$. Thus, significant academic and industrial research of methods to stabilize and expand the application possibilities for the various natural food colorants is ongoing. Most developments that food color manufacturers proclaim are vehicles for delivering established natural pigments into food products [7]. The challenges are to extract and transport the colorants using clean technologies. Thus, recent studies have focused on increasing the means of extraction and availability of bioactive compounds using non-environmentally harmful technologies [8-12].

Normally, the chemical stability of food pigments is markedly affected by several external factors [3], such as $\mathrm{pH}$, temperature, light, oxygen, and solvents, as well as the presence of enzymes, proteins and metallic ions in food products.

Research in Food Science generally falls under the following topics for study: (1) influencing factors that improve the stability of natural colorants; (2) investigations of new raw materials to extract colorants or increase the pigment content; (3) assessing and improving stability; (4) industry processing effects on colorants, and (5) health effects [13].

The objective of this paper is to provide an updated overview that shows the trends of research to improve the 
availability of colorants, the challenges associated with this endeavor, and progress over the past 10 years $(2008-2018)$.

\section{Overview of Colorants in the Food Industry}

The natural colorants market is projected to be $\$ 1.7$ billion by 2020 [13]. Color is the first sensory attribute by which foods are judged by consumers, influencing the purchase decision. Consequently, it is widely used in the food industry to meet consumer expectations, due to their habitual association of color with the taste, smell or quality of the product.

Some natural colorants include: annatto, anthocyanins, betaines, betacyanins, chlorophylls, caramel, cochineal, curcumin and other phenolic compounds, carminic acid, genipin, lycopene and carotenoids [2, 14]. These natural colorants are applied in the food industry in the form of extracts or concentrates that contain natural raw materials of vegetable origin. The colorant is extracted from a part of the plant such as leaves, roots, flowers, rhizomes, peels or fruits [15], which are the most common sources. However, there are other sources of natural colorants such as algae, insects and microorganisms $[16,17]$.

To obtain the extracts, there are many choices based on the chemical characteristics of the colorant, the raw material, the vegetable part where the colorant is found and the final application of the pigment. The majority of the extraction processes use organic solvents [18]; however, attention should be paid to the use of nontoxic solvents when the colorant is intended for food. To select the most suitable solvent, it is important to determine the nature of compounds that are to be isolated or extracted. To extract hydrophilic compounds, polar solvents such as methanol, ethanol or ethyl-acetate can be used; for the extraction of lipophilic compounds, dichloromethane or a mixture of dichloromethane/methanol in ratio of 1:1 are frequently used [17]. Several methods including sonification, heating under reflux, and Soxhlet extraction are commonly used depending on the target compound's polarity and thermal stability. Some modern methods are also used for extraction, such as solid-phase microextraction, supercritical fluid extraction, pressurized-liquid extraction, microwave-assisted extraction, solid-phase extraction and surfactant-mediated techniques, which have advantages in terms of yield and easy collection of extracts [17, 19]. Now, due to decreasing fossil resources (such as petroleum) and rising energy prices, researchers are being challenged to find new technologies to reduce or eliminate the consumption of solvents during extraction [20]. In addition, many extractions demand nonrenewable energy sources that can introduce effluents into the atmosphere that contain substantial amounts of pollutants such as aldehydes and free fatty acids. Another disadvantage is that conventional extraction methods are time consuming: some processes require several hours to achieve a complete extraction [21]. Additionally, attention should be paid to the use of nontoxic solvents when the colorant is intended for food. Therefore, the transition to alternative, green techniques to replace conventional extraction methods is attractive as a research topic due to advantages that correspond to reduced energy needs and resorting to nonhazardous substitute solvents and renewable natural products while ensuring a safe and high-quality extracts. Some non-conventional extraction techniques provide such advantages and are also efficient technologies at low cost [18, 21-23].

In addition to obtaining colorants by plant matrices, microorganisms produce various coloring compounds [24]. The pigment most commonly used in industries is beta-carotene, which is obtained from a cyanobacteria. Microorganisms that have the ability to produce pigments in high yields include species of Monascus, Paecilomyces, Serratia, Cordyceps, and Streptomyces, for example [25]. However, due to difficulties with the introduction of microbial pigments on the market (because of the possibility of mycotoxin), only a small number of these colorants are produced industrially. There are also colorants that are obtained from animals. For example, Cochineal Carmine is obtained from the dried bodies of females of scaled insect species, namely, Dactylopius coccus Cost [26].

\section{Stages for Maintaining the Accessibility and Availability of Colorants}

There are several critical points throughout production, from extraction to storage of the colorant, that lead to its disintegration. The degradation of the colorant affects so much of its color that it sensorially damages the product, as well as its bioactive compounds. The preservation of these characteristics is a major challenge for science and the food industry. It is necessary, therefore, to separate each critical point, aiming at studying strategies to overcome these problems.

\subsection{Extraction}

The first critical point is related to natural colorant extraction. Some studies have been applied to optimize the extraction of natural pigments, in order to maintain their characteristics and avoid the loss of color and bioactive compounds in the pigments [27-32]. Table 1 shows different colorants, their origin, types of innovative extraction methods and processing conditions from recent studies.

Losses can occur based on how aggressive the extraction process is [27], as well as the temperature at which extraction occurs. The inadequate choice of solvent, inadequate choice of method and the complexity of the matrix from which the colorant should be extracted may hinder the extraction when there are strong domains of interaction between the matrix and the pigment $[20,33]$. Therefore, it is necessary to 
carefully study the characteristics of the matrix where the colorant is obtained and its interaction with the solvent. Similarly, knowing the characteristics of the colorant helps in choosing the solvent and the appropriate extraction method, as well as the maximum temperature that can be reached. It is important to emphasize the importance of being a nontoxic solvent, applicable in food, which limits the range of extraction options [15, 34]. It is possible to perceive the complexity of obtaining a suitable extraction method with conditions that will lead to an excellent extraction yield and maintains the characteristics of the colorant.

In this context, there are several extraction methods that focus on better preserving the pigment characteristics. Additionality more recent developments concern the use of non-thermal concepts to facilitate the extraction without risking overheating of the matrix while decreasing energy use. Therefore, there has been an increase in the application of non-conventional and emerging technologies to extract various classes of bioactive compounds. Another type of extraction method, aimed at reducing aggressive risk to the environment, named "green extraction" is a new concept that reduces energy consumption, allows the use of alternative solvents and ensures a safe and high-quality extract. Traditional techniques are time consuming, lack efficiency in extracting the target analytes and require large volumes of non-environmentally friendly organic solvents, sorbents and samples. Traditional solid liquid extraction (SLE) methods include Soxhlet extraction, maceration and turbo-extraction (high-speed mixing). On the other hand, supercritical fluid extraction (SFE), ultrasound-assisted extraction (UAE), microwave-assisted extraction (MAE), and pressurized liquid extraction (PLE) are examples of innovative green extraction techniques [50].

Table 1. Studies published on the application of non-conventional technologies to extract colorants compounds

\begin{tabular}{|c|c|c|c|c|c|}
\hline Colorant & Species & $\begin{array}{l}\text { Part of } \\
\text { the plant }\end{array}$ & Extraction & Process conditions & Reference \\
\hline Bixin & Bixa orellana & seeds & Ultrasound & Ethanol, $40 \mathrm{kHz}, \mathrm{S} / \mathrm{F}: 19$ & [28] \\
\hline Bixin & Bixa orellana & seeds & $\begin{array}{l}\text { Low pressure solvent } \\
\text { extraction }\end{array}$ & Ethanol, $95 \mathrm{~min}, \mathrm{~S} / \mathrm{F}: 8,333 \mathrm{~K}$ & [29] \\
\hline Bixin & Bixa orellana & seeds & Microwave & Water, $900 \mathrm{~W}, 2450 \mathrm{MHz}$ & {$[30]$} \\
\hline Bixin & Bixa orellana & seeds & $\begin{array}{l}\text { Low pressure solvent } \\
\text { extraction }\end{array}$ & Ethanol, S/F: 8, $333 \mathrm{~K}$ & [31] \\
\hline Bixin & Bixa orellana & seeds & $\begin{array}{l}\text { Supercritical fluid } \\
\text { extraction } \mathrm{CO}_{2}\end{array}$ & $\mathrm{~S} / \mathrm{F}: 35,333 \mathrm{~K}, 31 \mathrm{MPa}$ & [35] \\
\hline Bixin & Bixa orellana & seeds & $\begin{array}{l}\text { Low-pressure solvent } \\
\text { extraction }\end{array}$ & Ethanol, $20 \mathrm{~min}, \mathrm{~S} / \mathrm{F}: 8,333 \mathrm{~K}$ & [36] \\
\hline Curcumin & Curcuma longa & rhizome & $\begin{array}{l}\text { Supercritical fluid } \\
\text { extraction } \mathrm{H}_{2} \mathrm{O}\end{array}$ & $13 \mathrm{~min}, 413 \mathrm{~K}, 1.5 \mathrm{MPa}, 0.7 \mathrm{~mm}$ of particles & [37] \\
\hline Curcumin & Curcuma longa & rhizome & $\begin{array}{l}\text { Pressurized liquids } \\
\text { extraction }\end{array}$ & Ethanol, S/F: 9.5, $333 \mathrm{~K}, 10 \mathrm{MPa}$ & [32] \\
\hline Curcumin & Curcuma longa & rhizome & $\begin{array}{l}\text { Ironic liquid based } \\
\text { ultrasonic }\end{array}$ & $\begin{array}{l}\text { [OMIM]Br concentration: } 4.2 \mathrm{~mol} / \mathrm{L} \text {, } \\
\text { liquid-raw ratio: } 30 \mathrm{~mL} / \mathrm{g}, 90 \mathrm{~min}, 250 \mathrm{~W}\end{array}$ & [38] \\
\hline Curcumin & Curcuma longa & rhizome & Supercritical water & $100 \mathrm{~min}, 373 \mathrm{~K}, 3 \mathrm{MPa}$ & [39] \\
\hline Curcumin & Curcuma longa & rhizome & Microwave & Ethanol, $15 \mathrm{~min}, 348 \mathrm{~K}, 1500 \mathrm{~W}$ & [40] \\
\hline Curcumin & Curcuma longa & rhizome & Ultrasound & $5 \mathrm{~min}, \mathrm{~S} / \mathrm{F}: 4.294 \mathrm{~K}, 150 \mathrm{~W}$ & [41] \\
\hline Curcumin & Curcuma longa & rhizome & Ultrasound & $35^{\circ} \mathrm{C}, \mathrm{S} / \mathrm{F}: 5,250 \mathrm{~W}, 22 \mathrm{kHz}$ & [42] \\
\hline Curcumin & Curcuma longa & rhizome & $\begin{array}{l}\text { Ultrasound and } \\
\text { microwave }\end{array}$ & Ethanol, $7 \mathrm{~min}, 80 \mathrm{~W}, 245 \mathrm{MHz}$ & [43] \\
\hline Anthocyanin & Myrciaria cauliflora & peel & $\begin{array}{l}\text { Supercritical carbon } \\
\text { dioxide }\end{array}$ & Ethanol (cosolvent), $333 \mathrm{~K}, 20 \mathrm{MPa}$ & [44] \\
\hline Anthocyanin & Myrciaria cauliflora & peel & Ultrasound & $\begin{array}{c}\text { Ethanol, } 10 \mathrm{~min}, \mathrm{~S} / \mathrm{F}: 20,303 \mathrm{~K}, 25 \mathrm{kHz}, 150 \\
\text { W, (ultrasound bath: } 2.7 \mathrm{~L} \text { ) }\end{array}$ & [45] \\
\hline Anthocyanin & Myrciaria cauliflora & peel & $\begin{array}{l}\text { Pressurized liquid } \\
\text { extraction }\end{array}$ & Ethanol, $353 \mathrm{~K}, 5 \mathrm{MPa}$ & [46] \\
\hline Anthocyanin & Crocus sativus & petals & Solvent: ethanol & $\mathrm{S} / \mathrm{F}: 20,298.9 \mathrm{~K}, 24 \mathrm{~h}$ & [47] \\
\hline Anthocyanin & Vitis labrusca B & peel & $\begin{array}{l}\text { Supercritical carbon } \\
\text { dioxide }\end{array}$ & Ethanol, $318 \mathrm{~K}, 16$ and $18 \mathrm{MPa}$ & [48] \\
\hline Betacyanin & Beta vulgaris & red beets & Microwave & 1:1: ethanol/water, $16.67 \mathrm{~min}, 800 \mathrm{~W}$, & [49] \\
\hline
\end{tabular}




\subsubsection{Supercritical-Fluid Extraction (SFE)}

SFE technology is a viable solution for a clean and low-cost technology in which it is possible to recycle the solvent, as well as use non-toxic solvents with a high extraction efficiency [15]. When using this technology, it is possible to control the parameter changing conditions of extraction, providing the possibility of more applications of specific components and improving the efficiency of the extraction. The selection of these conditions depends on the compound, the matrix where the compound is found and the verification of the best parameter from the extraction efficiency.

SFE depends on the solvating properties of a supercritical fluid, which can be obtained by applying pressure and temperature above the critical point of a substance. Each compound will have a unique critical point [51]. This process consists of extraction of soluble substances from the solid substratum by the supercritical solvent, followed by separation of these compounds from the supercritical solvent after the expansion [15].

SFE depends on fluid conditions such as temperature and pressure, which are the most commonly altered parameters in the process for optimization. In addition, some extrinsic features such as the characteristics of the sample matrix, interaction with targeted analytes and many environmental factors [51]. With regard to the solvent, carbon dioxide is the solvent most widely used in SFE because it is reasonably safe, nontoxic and has feasible supercritical conditions with low temperature and pressure [52]. Supercritical $\mathrm{CO}_{2}$ $\left(\mathrm{ScCO}_{2}\right)$ is also attractive because of its high diffusivity and its easily tunable solvent strength. It is possible to obtain $\mathrm{ScCO}_{2}$ at $304.2 \mathrm{~K}$ and $7.39 \mathrm{MPa}[15,53]$.

\subsubsection{Ultrasound-Assisted Extraction (UAE)}

UAE is considered to be a nonconventional method that has demonstrated efficacy in extracting active compounds, introducing advantages such as low process times and high yields compared to traditional methods [54, 55]. Ultrasonic energy has been identified as an efficient tool to improve performance in different applications of analytical chemistry, such as the extraction of compounds. The improvement in extraction efficiency using ultrasonication is based on the phenomenon of cavitation, which occurs due to the application of low frequency ultrasound. This causes intense shear rates because it promotes the formation and subsequent collapse of microbubbles associated with extreme levels of highly localized turbulence $[23,56]$. This ruptures the cell walls, facilitating a reduction in particle size and providing an increase in the surface area and channels of the solid for solvent access, resulting in higher mass transfer [23]. Additionally, although not detailed as a mechanism, the intense mixing effect generated by the propagation of ultrasound in the liquid medium contributes to enhancing mass transfer, greatly improving the solute transfer rate [54]. The capability of ultrasound to cause cavitation depends on its frequency and intensity; extract and solvent properties such as viscosity and surface tension; as well as temperature and pressure conditions [42]. For example, vapor pressure governs the intensity of collapse, whereas surface tension and viscosity govern the transient threshold of cavitation [54].

In general, scientific interest in the use of ultrasound to assist extraction has increased in the past decade [54]. UAE is a clean method that avoids the use of a large quantity of solvent and voluminous extraction vessels such as Soxhlet and maceration. The reduced environmental impact of UAE is clearly advantageous in terms of energy and time. The use of solvents is low, and the processing time at high power can be only minutes [23]. The application of ultrasound extends the range of solvent choice that may replace toxic organic solvents with GRAS (Generally Recognized as Safe) solvents. The selection of GRAS solvents provides several safety benefits and reduces the cost and environmental impacts of the extraction process. Ultrasound improves the extraction efficiency of solvents that have poor extractability using conventional methods [54].

\subsubsection{Microwave-Assisted Extraction (MAE)}

Microwaves are electromagnetic waves, generally used at $2.45 \mathrm{GHz}$, which induce heating inside the material via ionic conduction and dipolar rotation of molecules. Ionic conduction is the electrophoretic migration of ions when an electromagnetic field is applied [57]. Dipolar rotation is due to the alignment on an electric field of molecules that possess a dipole moment (either permanent or induced by the electric field) in both the solvent and the solid sample. This oscillation produces collisions with surrounding molecules and thus, the liberation of thermal energy into the medium [40].

In MAE, the moisture inside the cell is heated and its evaporation increases the porosity of the biological matrix, which in turn allows for better penetration of a solvent $[58,59]$. The elevated temperature also generally increases solubility and improves yield. The main advantage is a reduction in the extraction time and solvent use. However, the high temperature can destroy the bioactive compounds [60]. As such, is reasonable to control these parameters to find a suitable extraction temperature (where the increase in extraction kinetics compensates the degradation reactions) is clear, as is the importance of contextualizing it with the tissue that constitutes the matrix [61]. Generally, to avoid overheating, low to moderate powers (coupled with longer extraction times) are used [62].

MAE allows for lower extraction times, requires less solvent and exhibits good reproducibility $[58,63]$. On the other hand, the augmentation of compound diffusion from the matrix to the solvent, while potentially growing the extraction yield, also enables the extraction of non-targeted compounds [63].

In general, MAE has the following advantages: rapidity; reductions in solvent consumption; better chance of control, and automation. Microwave-assisted extraction is also 
environmental friendly, since it requires less energy and can efficiently use nontoxic solvents [64].

\subsubsection{Pressurized Liquid Extraction (PLE)}

PLE, also known as accelerated solvent extraction (ASE), allows for the fast extraction of compounds with little solvent consumption [18]. In this method, high pressure is used to maintain the liquid solvents at higher temperatures (frequently, temperatures above the boiling point of the solvent), which allows for improvement in the solubility of the compounds, sample wetting and matrix penetration. These conditions improve analyte solubility and the kinetics associated with desorption from matrices [50, 65].

Extraction performed by PLE is an environmentally conscious technology that obtains high yields despite using significantly lower amounts of solvents than conventional technics. In addition, this process is selective because it is possible to extract either polar or nonpolar compounds, depending on the characteristics of the solvents that are used [50]. This process facilitates the use of environmentally friendly solvents, and therefore, PLE is considered to be a green technology. For example, PLE promotes water as an extraction solvent. Pressurized water extraction is a nonconventional method, and the major property of this technique is using temperature and pressure values above $373 \mathrm{~K}$ and $0.1 \mathrm{MPa}$ (the atmospheric boiling point of water), as well as below the water critical point values $(647 \mathrm{~K}, 22.1$ MPa) [59].

\subsubsection{Remarks}

All these techniques are used to extract bioactive substances to shorten processing time, reduce solvent consumption, increase the extraction yield and improve the quality of extracts. They are all more efficient compared to conventional methods, providing a great argument for using these technologies for improving the availability of colorants while having a low impact on the environment. Consequently, these techniques have the ability to replace conventional systems.

There are studies that have also used combined methods [23]. The combination of methods can improve the efficiency of extraction. The combination of UAE and MAE is one of the most promising hybrid techniques for fast, efficient extractions. UAE promotes the release of soluble compounds from the plant by disrupting cell walls, facilitating solvent access to the cell contents. In addition, microwaves heat the entire sample very quickly, inducing the migration of dissolved molecules [23].

\subsection{Food Process}

When the colorant extract is incorporated into food matrices, sometimes the extract must be dried to facilitate its incorporation or storage until its use. During this procedure, it is important to verify that there is no sensory or bioactive compounds degradation. After the incorporation of the extract, the industrial processing unfortunately causes alteration, degradation, or even loss of food color. The factors that influence the stability of natural pigments during processing are $\mathrm{pH}$, temperature, water activity, oxygen, metals, solvents, the presence of enzymes and ion radiation [13]. These factors are discussed below.

\subsection{1. $\mathrm{pH}$}

Each pigment has an accepted $\mathrm{pH}$ range that does not cause degradation and the loss of properties (Table 2). The bioactive proprieties may not be affected, but the color can change with $\mathrm{pH}$ variation [66]. In general, at $\mathrm{pH}$ range of 3 to 5 , suggested for use in acidic foods, can affect natural colorants [13]. For example, betalains are stable in extracts at $\mathrm{pH} 5$, but below $\mathrm{pH} 3$, the color of betanin moves toward violet, and above $\mathrm{pH} \mathrm{7,} \mathrm{the} \mathrm{color} \mathrm{shifts} \mathrm{toward} \mathrm{blue} \mathrm{due} \mathrm{to} \mathrm{the}$ longer wavelength [67].

\subsubsection{Water Activity}

Water activity controls the rate of biochemical conversion. Water activity affects the stability of colorants stability by controlling the water-dependent hydrolytic reactions for bond cleavage [67].

\subsubsection{Temperature}

Thermal processing is used in the development of different processed products. Temperature affects the stability of pigments, and increases in temperature result in degradation [68]. However, thermal degradation is also affected by the temperature range, the extent of heating, the presence of oxygen, and the concentration of pigments. The application of these colorants is limited in foods that require thermal processing such as pasteurization or blanching [69].

\subsubsection{Light}

Color is oxidized and degraded in presence of light. There is a reverse relationship between light intensity and colorant stability [70]. Immersion in UV and visible light excites electrons of the colorant chromophores to a more energetic state, initiating higher reactivity or lowered activation energy of the molecule [67].

\subsubsection{Metal}

Some metal cations were identified to facilitate or accelerate pigment degradation, such as iron, copper, tin, aluminum, etc. An early study indicated that juice is less vulnerable to metal ions because of the presence of metal complexing agents. Chelating agents (citric acid and EDTA) were reported to stabilize colorants against metal-catalyzed degradation [67]. For example, the presence of metals assists as catalysts for the oxidation reactions of polyphenols and carotenoids [13].

In addition to the process during which the colorant is applied, the incorporation of bioactive compounds in different food matrices is limited by its inherent characteristics, such as flavor and incompatibility with the matrix, as well as the formulation and other ingredients that 
are introduced, which can affect the stability of bioactive compounds [71].

In this way, it is important to protect the colorant or create strategies for it to be applied after the processing. Therefore, it is important to study the processing of the food and the tolerable range of bioactive compounds to prevent possible losses of natural pigment.

Table 2. Main natural pigments from different vegetable matrices and parameters that affect their stability

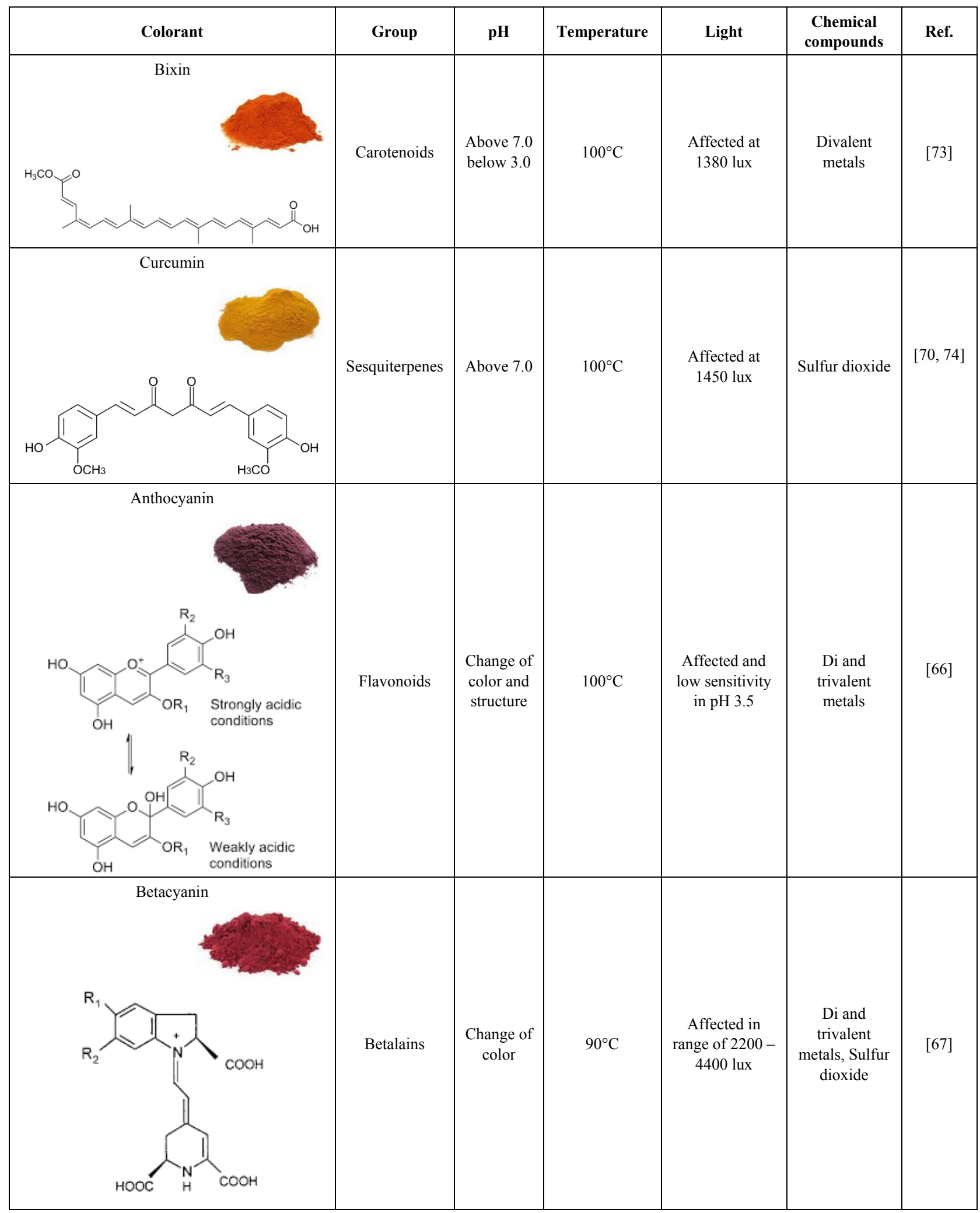




\subsection{Storage}

The fourth critical point is the stability of the extract during storage, given its sensitivity to variations in light, water activity and elevated temperatures. Stability during storage includes oxidative stability, thermal stability, hygroscopicity, etc. [72]. For this concern, modern food processing and packaging techniques have been developed to improve the shelf life of natural products [2, 13, 68]. Packaging shall protect the colorants from light, temperature, oxygen and other components which may react with the colorant. It is difficult for the colorant to remain stable in the environment, so it is necessary to create strategies for its protection.

\subsection{Solution to Improve Availability after Extraction}

After obtaining extracts using technologies that promote the lowest possible degradation to the compounds, the stabilization of the natural colorants for their application in food products is one of the biggest challenges for the productive sector. It is necessary to use other techniques that will provide physical and chemical stability, so as not to impair the color sensory characteristics during food processing and storage. As previously stated, the extract obtained passes through a drying process to facilitate its application, which we named micronization of the extract. It is a process of obtaining particles of the active compounds. Micronization can be accomplished by various techniques. But also, in search of obtaining a system that will confer protection to the colorant, the process of encapsulation is the most appropriate one. In which an encapsulating matrix retard or prevent degradations of the colorant.

Encapsulation technology has been used in the food industry to (i) overcome solubility incompatibilities between ingredients, (ii) protect sensitive ingredients such as natural colorants from degradation during processing and storage, (iii) increase their bioavailability, including the controlled release of encapsulated compounds, and (iv) provide an effective barrier for environmental and/or chemical interactions until release is desired [68]. Encapsulation can preserve a substance in a finely divided state and to release it as occasion demands. The encapsulation techniques makes the stabilization of many ingredients viable, expanding the application of functional products in the global market [19, 75-78].

Majority systems may encapsulate compounds with defensive particulate structures, such as colloidal forms (self-assembly), liquid droplets (emulsion), soft microparticles (microbeads), solid particles (dried) or co-precipitation using $\mathrm{ScCO}_{2}$.

There are several encapsulation forms that have both advantages and limitations, and selection depends on the characteristics of the bioactive components (molecular weight, polarity) and, consequently, the desired physicochemical properties of the encapsulate, such as solubility, partitioning, and stability. In addition to the usual characteristics exhibited and shared with other food powders (e.g., particle size and surface morphology), the encapsulate should contain a significant amount of the bioactive component in a form that can be easily incorporated into food matrices, can protect the material against degradation (throughout the food processing chain and in vivo) to ensure that it will remain in its active form, and can be compatible with the food matrix in which it is applied. Other conditions that should also be considered when selecting the appropriate technique are the time, cost, and steps required for preparation, production volume, market requirement, and regulations $[77,79]$. Therefore, it is important to evaluate the best technique that protects the active material and promotes some applications. In addition, the choice of the most suitable encapsulation process is also important for the permanence of the colorant properties during storage [71].

Although encapsulation technologies are widely studied by the scientific community and some their applied industrially, studies concerning the particle design with controlled physical properties (size, morphology, solubility, thermal stability, and others) still need to be developed. Particle engineering may lead to an increase in the effectiveness of the encapsulating system [80]. Some encapsulation technologies do not allow the control of the particle characteristics during the manufacturing process as the spray-drying process and the freeze-drying process, for instance. It occurs because the process parameters in these technologies have little influence on the technological properties of the particles formed. In addition, conventional technologies, as the spray-drying, are thermal processes performed at high temperatures $\left(150-210^{\circ} \mathrm{C}\right)$ or on the other hand are very expensive, as the freeze-drying technology.

Considering the deficiencies of most encapsulation techniques, the ideal process would be non-thermal and allow the production of particles with controlled properties through the engineering of particles. In this context, supercritical technology would be an ideal process.

Supercritical technology is attractive due to the characteristics of supercritical carbon dioxide $\left(\mathrm{ScCO}_{2}\right)$, with low critical properties that are relatively mild of 304.25 K and 7.39 MPa, which allow for the realization of a non-thermal encapsulation process that will consequently increase the availability of the colorant and respective bioactive actions. In addition, it allows for variable parameters that assist in the production of particles with controlled properties, such as size, morphology and composition [80]. It has been a trend to use supercritical technology for particle production because of these advantages. One more positive aspect of encapsulation by supercritical fluids is that the great interest in the use of supercritical technology lies in the possibility of varying the parameters of the process, such temperature, pressure, injector nozzle diameter, solvent characteristics, solubility of the solute in $\mathrm{ScCO}_{2}$ and nature of the solute-solvent interaction [81]. Producing particles with various characteristics and the guarantee that the process does not risk de-stabilization of the encapsulated or micronized bioactive compounds. That is, the supercritical process 
technology allows for the stabilization of bioactive compounds in a non-thermal way [82]. Another important advantage of the production of colorant particles by supercritical technology is that very small particles can be produced. This is because color strength is enhanced when the coloring matter is obtained in very small submicronic particles [82].

Another important aspect that makes supercritical technology an excellent alternative for the production of particles with controlled properties is associated with its versatility of operation and functions in the precipitation process. Supercritical fluid can act as a solvent (Rapid expansion of supercritical solution (RESS), Rapid expansion of a supercritical solution into a liquid solvent (RESOLV), Rapid expansion of supercritical solution into an aqueous solution (RESSAS) and Rapid expansion of supercritical solution with a nonsolvent (RESS-N); antisolvent: Gas antisolvent (GAS), Supercritical antisolvent (SAS), Aerosol solvent extraction system (ASES), Solution enhanced dispersion by supercritical fluids (SEDS) and Particles by compressed antisolvent (PCA)); cosolvent (Gas saturated solutions (PGSS), Gas assisted melting atomization (GAMA) and Depressurization of an expanded liquid organic solution (DELOS)); or extractor and antisolvent (Supercritical fluid extraction of emulsions (SFEE)) [90].

As in the extraction process, it is important that the particle production process is also safe for the environment. As with the processes mentioned above, if the GRAS solvent is used, it can be classified as Green Technology. In Table 3, we show examples of studies that have used supercritical technology for the precipitation of colorants.

There are still many studies that use micronization and encapsulation of natural colorants, despite being a technique that exists in the literature for more than 10 years [91, 92]. This demonstrates how much can still be exploited for the better availability of several colorants.

Table 3. Studies using supercritical fluid technology to obtain colorant particles

\begin{tabular}{|c|c|c|c|c|}
\hline Process & Colorant & Encapsulant material & Better conditions & Reference \\
\hline SAS & Curcumin & $\begin{array}{l}\text { Eudragit }{ }^{\circledR} \text { L100, Pluronic } \AA \text { F } 127 \text {, } \\
\text { and polyvinylpyrrolidone or mixture }\end{array}$ & $\begin{array}{l}10 \mathrm{MPa}, 313 \mathrm{~K} \text {, solution flow } 1 \mathrm{~mL} / \mathrm{min}, \mathrm{CO}_{2} \text { flow: } \\
2 \mathrm{~kg} / \mathrm{h} \text {. }\end{array}$ & {$[78]$} \\
\hline GAS & Curcumin & $*$ & $10 \mathrm{MPa}, 298-300 \mathrm{~K}, \mathrm{CO}_{2}$ flow: $20 \mathrm{~mL} / \mathrm{min}$ & [83] \\
\hline SEDS & $\beta$-Carotene & $*$ & $\begin{array}{l}\text { 9.4 MPa, } 308 \mathrm{~K} \text {, solution flow: } 1 \mathrm{~mL} / \mathrm{min}, \mathrm{CO}_{2} \text { flow: } \\
1.5 \mathrm{~kg} / \mathrm{h}\end{array}$ & {$[84]$} \\
\hline SEDS & $\beta$-Carotene & * & $\begin{array}{l}8 \text { - } 20 \mathrm{MPa}, 313 \mathrm{~K} \text {, solution flow: } 1 \mathrm{~mL} / \mathrm{min}, \mathrm{CO}_{2} \\
\text { flow: } 40 \mathrm{~mL} / \mathrm{min}\end{array}$ & {$[85]$} \\
\hline DELOS & Anthocyanin & Lecithin and cholesterol & $30 \mathrm{MPa}$, depressurization: $9000 \mathrm{a} / \mathrm{min}, 323 \mathrm{~K}$ & {$[86]$} \\
\hline SAS & Anthocyanin & $\begin{array}{l}\text { biodegradable polymer } \\
\text { polyvinylpyrrolidone }\end{array}$ & $\begin{array}{l}12.5 \mathrm{MPa}, 308-313 \mathrm{~K} \text {, solution flow: } 6 \mathrm{~mL} / \mathrm{min} \text {, } \\
\mathrm{CO}_{2} \text { flow: } 2 \mathrm{~kg} / \mathrm{h}\end{array}$ & {$[87]$} \\
\hline SAS & Curcumin & $*$ & $\begin{array}{l}10 \mathrm{MPa}, 313 \mathrm{~K} \text {, solution flow: } 500 \mathrm{~g} / \mathrm{h}, \mathrm{CO}_{2} \text { flow: } \\
500 \text { and } 800 \mathrm{~g} / \mathrm{h}\end{array}$ & {$[88]$} \\
\hline $\mathrm{SF}-\mathrm{CO}_{2}$ & All-trans-lycopene & $*$ & $32 \mathrm{MPa}, 323 \mathrm{~K}$ & [89] \\
\hline SAS & Curcumin & Polyethylene glycol & $\begin{array}{l}10 \mathrm{MPa}, 313 \mathrm{~K} \text {, solution flow: } 1 \mathrm{~mL} / \mathrm{min} \mathrm{CO}_{2} \text { flow: } \\
0.5 \text { and } 1 \mathrm{~kg} / \mathrm{h}\end{array}$ & [9] \\
\hline
\end{tabular}

*Micronization (without encapsulant material)

\section{Perspectives on Natural Colorants}

In addition to the concern for maintaining stable colorant, the trends in obtaining colorants (in both the extraction and particle production processes) must be framed in the context of green technologies. The basic principles of green processes are as follows: (1) use of renewable plant resources; (2) use of "GRAS-solvents"; (3) low energy consumption; (4) study of the use of post extraction co-products; and (5) reduction of operations that produce waste and gases to atmosphere [24]. Therefore, scientific research should focus on green technology.

There is also great concern regarding the solvent to be used; the selection of a suitable solvent is based on the safety of those handling the extraction and is made to avoid toxicity, carcinogenicity, mutagenicity, absorption through the skin and respiratory system, safety of the process. In addition, the solvent must not be flammable or explosive, and must promote environmental protection and process sustainability (recycling and reuse capacity) [27].

There are no doubts that the natural world is rich in color pigments and that most plants have not yet been exploited for their coloring properties/abilities. Thus, new naturally derived food pigments are prepared to satisfy consumer expectations. In parallel with this, increasingly effective techniques are needed to retain the stability of natural food pigments and to ensure the final attractiveness of enriched-foodstuffs during the manufacturing and processing practices, as well as during storage [2].

In general, and despite current advances in the field of food science, many other natural sources of food pigments must be evaluated for their coloring properties, whereas for sufficient quantities they should be made available mainly for extraction and subsequent use [2].

Therefore, the search for new plant extracts and studies aimed at better stability will be the trend of future research, 
ultimately to increase the possibility of using natural colorants and their bioactive properties.

\section{Concluding Remarks}

The interest in the health benefits of natural pigments is a strong justification to study ways of improving their retention as natural constituents of foods during processing and storage and for their use as food additives.

As a suggestion for improving studies of the availability of colorants, we suggest the following: (1) using clean technology for extraction and encapsulation; (2) focusing on parameter studies to find optimum particle production conditions; (3) considering a phase transitions study of the food matrices to have a better application destination, which implies making a more detailed characterization of the particles produced; (4) studying how the processes can affect the active compound; (5) studying the bioavailability of compounds and (6) considering the recycling of solvent ethanol.

Therefore, as observed in this review, we highlight that supercritical technology can meet the requirements for better availability of colorants. The technique can be used from extraction to pigment encapsulation. The technique has several advantages, such as the possibility of studying parameter variability and that supercritical fluid use is a nonthermal process, which do not degrade the pigment in any of the phases. These results demonstrate that this technology supports the demands of the market in improving the retention of natural colorants during processing and storage.

\section{ACKNOWLEDGEMENTS}

M. I. L. Neves thanks CAPES/DEA/PROEX for the Ph.D. assistantship, Eric Keven Silva thanks FAPESP for postdoctoral assistantship (2015/22226-6) and M. Angela A. Meireles thanks $\mathrm{CNPq}$ for the productivity grant (302423/2015-0).

\section{REFERENCES}

[1] M. Carocho, P. Morales, I.C.F.R. Ferreira, Natural food additives: Quo vadis?, Trends in Food Science \& Technology, 45 (2015) 284-295.

[2] N. Martins, C.L. Roriz, P. Morales, L. Barros, I.C.F.R. Ferreira, Food colorants: Challenges, opportunities and current desires of agro-industries to ensure consumer expectations and regulatory practices, Trends in Food Science \& Technology, 52 (2016) 1-15.

[3] G.T. Sigurdson, P. Tang, M.M. Giusti, Natural Colorants: Food Colorants from Natural Sources, Annual Review of Food Science and Technology, 8 (2017) 261-280.
[4] B. Gordillo, G.T. Sigurdson, F. Lao, M.L. Gonzalez-Miret, F.J. Heredia, M.M. Giusti, Assessment of the color modulation and stability of naturally copigmented anthocyanin-grape colorants with different levels of purification, Food research international, 106 (2018) 791-799.

[5] R. Cortez, D.A. Luna-Vital, D. Margulis, E. Gonzalez de Mejia, Natural Pigments: Stabilization Methods of Anthocyanins for Food Applications, Comprehensive Reviews in Food Science and Food Safety, 16 (2017) 180-198.

[6] J. Premkumar, R. Thottiam Vasudevan, Bioingredients: functional properties and health impacts, Current Opinion in Food Science, 19 (2018) 120-128.

[7] T. Coultate, R.S. Blackburn, Food colorants: their past, present and future, Coloration Technology, 134 (2018) 165-186.

[8] G. Náthia-Neves, A.G. Tarone, M.M. Tosi, M.R. Marostica Junior, M.A.A. Meireles, Extraction of bioactive compounds from genipap (Genipa americana L.) by pressurized ethanol: Iridoids, phenolic content and antioxidant activity, Food research international, 102 (2017) 595-604.

[9] Á.L. Santana, M.A.A. Meireles, Coprecipitation of turmeric extracts and polyethylene glycol with compressed carbon dioxide, The Journal of Supercritical Fluids, 125 (2017) 31-41.

[10] G.L. Zabot, I.P. Bitencourte, M.V. Tres, M.A.A. Meireles, Process intensification for producing powdered extracts rich in bioactive compounds: An economic approach, The Journal of Supercritical Fluids, 119 (2017) 261-273.

[11] S.C. Alcázar-Alay, F.P. Cardenas-Toro, J.F. Osorio-Tobón, G.F. Barbero, M.A.d.A. Meireles, Obtaining anthocyanin-rich extracts from frozen açai (Euterpe oleracea Mart.) pulp using pressurized liquid extraction, Food Science and Technology, 37 (2017) 48-54.

[12] S.C. Alcázar-Alay, J.F. Osorio-Tobón, T. Forster-Carneiro, M.A.A. Meireles, Obtaining bixin from semi-defatted annatto seeds by a mechanical method and solvent extraction: Process integration and economic evaluation, Food research international, 99 (2017) 393-402.

[13] D.B. Rodriguez-Amaya, Natural food pigments and colorants, in: Bioactive Molecules in Food, Springer, 2018, pp. 1-35.

[14] I.A. Neri-Numa, M.G. Pessoa, B.N. Paulino, G.M. Pastore, Genipin: A natural blue pigment for food and health purposes, Trends in Food Science \& Technology, 67 (2017) 271-279.

[15] C.G. Pereira, M.A.A. Meireles, Supercritical fluid extraction of bioactive compounds: fundamentals, applications and economic perspectives, Food and Bioprocess Technology, 3 (2010) 340-372.

[16] G. Náthia-Neves, M.A.A. Meireles, Genipap: A New Perspective on Natural Colorants for the Food Industry, Food and Public Health, 8 (2018) 21-33.

[17] M. Yusuf, M. Shabbir, F. Mohammad, Natural colorants: Historical, processing and sustainable prospects, Natural products and bioprospecting, 7 (2017) 123-145.

[18] D.T. Santos, C.L.C. Albuquerque, M.A.A. Meireles, Antioxidant dye and pigment extraction using a homemade 
pressurized solvent extraction system, Procedia Food Science, 1 (2011) 1581-1588.

[19] D.T. Santos, J.Q. Albarelli, M.M. Beppu, M.A.A. Meireles, Stabilization of anthocyanin extract from jabuticaba skins by encapsulation using supercritical $\mathrm{CO}_{2}$ as solvent, Food research international, 50 (2013) 617-624.

[20] F. Chemat, A.S. Fabiano-Tixier, M.A. Vian, T. Allaf, E. Vorobiev, Solvent-free extraction of food and natural products, TrAC Trends in Analytical Chemistry, 71 (2015) 157-168.

[21] R.P. da Silva, T.A. Rocha-Santos, A.C. Duarte, Supercritical fluid extraction of bioactive compounds, TrAC Trends in Analytical Chemistry, 76 (2016) 40-51.

[22] J.C.F. Johner, T. Hatami, M.A.A. Meireles, Developing a supercritical fluid extraction method assisted by cold pressing for extraction of pequi (Caryocar brasiliense), The Journal of Supercritical Fluids, 137 (2018) 34-39.

[23] F. Chemat, N. Rombaut, A.-G. Sicaire, A. Meullemiestre, A.-S. Fabiano-Tixier, M. Abert-Vian, Ultrasound assisted extraction of food and natural products. Mechanisms, techniques, combinations, protocols and applications. A review, Ultrasonics sonochemistry, 34 (2017) 540-560.

[24] W.A. Ahmad, W.Y.W. Ahmad, Z.A. Zakaria, N.Z. Yusof, Application of bacterial pigments as colorant, in: Application of Bacterial Pigments as Colorant, Springer, 2012, pp. 57-74.

[25] K. Malik, J. Tokkas, S. Goyal, Microbial pigments: a review, Int J Microbial Res Technol, 1 (2012) 361-365.

[26] Y. Luo, M. Li, J. Du, Esterification of Cochineal Carmine Used For Dyeing Cationic Modified Cotton with High Color Fastness, Journal of Engineered Fabrics \& Fibers (JEFF), 12 (2017).

[27] M. Cvjetko Bubalo, S. Vidović, I. Radojčić Redovniković, S. Jokić, New perspective in extraction of plant biologically active compounds by green solvents, Food and Bioproducts Processing, 109 (2018) 52-73.

[28] N.Q. Nguyen, T.Q. Dang, Optimization of Ultrasound-Assisted Extraction of Natural Pigments from Annatto Seeds (Bixa Orellana) Using Response Surface Methodology, EC Nutrition, 7 (2017) 159-169.

[29] G.L. Zabot, M.N. Moraes, M. Meireles, Process integration for producing tocotrienols-rich oil and bixin-rich extract from annatto seeds: A techno-economic approach, Food and Bioproducts Processing, 109 (2018) 122-138

[30] K. Sinha, S. Chowdhury, P.D. Saha, S. Datta, Modeling of microwave-assisted extraction of natural dye from seeds of Bixa orellana (Annatto) using response surface methodology (RSM) and artificial neural network (ANN), Industrial Crops and Products, 41 (2013) 165-171

[31] M.N. Moraes, G.L. Zabot, M.A.A. Meireles, Extraction of tocotrienols from annatto seeds by a pseudo continuously operated SFE process integrated with low-pressure solvent extraction for bixin production, The Journal of Supercritical Fluids, 96 (2015) 262-271.

[32] J.F. Osorio-Tobón, P.I. Carvalho, M.A. Rostagno, A.J. Petenate, M.A.A. Meireles, Extraction of curcuminoids from deflavored turmeric (Curcuma longa L.) using pressurized liquids: process integration and economic evaluation, The
Journal of supercritical fluids, 95 (2014) 167-174.

[33] Y. Yin, J. Jia, T. Wang, C. Wang, Optimization of natural anthocyanin efficient extracting from purple sweet potato for silk fabric dyeing, Journal of Cleaner Production, 149 (2017) 673-679.

[34] I. Viera, A. Pérez-Gálvez, M. Roca, Green Natural Colorants, Molecules, 24 (2019) 154.

[35] C.L. Albuquerque, M.A.A. Meireles, Defatting of annatto seeds using supercritical carbon dioxide as a pretreatment for the production of bixin: experimental, modeling and economic evaluation of the process, The Journal of Supercritical Fluids, 66 (2012) 86-95.

[36] L.M. Rodrigues, S.C. Alcázar-Alay, A.J. Petenate, M.A.A. Meireles, Bixin extraction from defatted annatto seeds, Comptes Rendus Chimie, 17 (2014) 268-283.

[37] M.V. Kiamahalleh, G. Najafpour-Darzi, M. Rahimnejad, A.A. Moghadamnia, M.V. Kiamahalleh, High performance curcumin subcritical water extraction from turmeric (Curcuma longa L.), Journal of Chromatography B, 1022 (2016) 191-198.

[38] J. Xu, W. Wang, H. Liang, Q. Zhang, Q. Li, Optimization of ionic liquid based ultrasonic assisted extraction of antioxidant compounds from Curcuma longa L. using response surface methodology, Industrial Crops and Products, 76 (2015) 487-493.

[39] T. Perko, M. Ravber, Ž. Knez, M. Škerget, Extraction of curcuminoids from turmeric (Curcuma longa L.) with subcritical water, Technologica Acta, (2016) 29.

[40] M. Bener, M. Özyürek, K. Güçlü, R. Apak, Optimization of microwave-assisted extraction of curcumin from Curcuma longa L.(Turmeric) and evaluation of antioxidant activity in multi-test systems, Records of Natural Products, 10 (2016) 542 .

[41] P.S. Wakte, B. Sachin, A. Patil, D. Mohato, T. Band, D. Shinde, Optimization of microwave, ultra-sonic and supercritical carbon dioxide assisted extraction techniques for curcumin from Curcuma longa, Separation and purification technology, 79 (2011) 50-55.

[42] S. Shirsath, S. Sable, S. Gaikwad, S. Sonawane, D. Saini, P. Gogate, Intensification of extraction of curcumin from Curcuma amada using ultrasound assisted approach: Effect of different operating parameters, Ultrasonics sonochemistry, 38 (2017) 437-445.

[43] M. Li, M.O. Ngadi, Y. Ma, Optimisation of pulsed ultrasonic and microwave-assisted extraction for curcuminoids by response surface methodology and kinetic study, Food chemistry, 165 (2014) 29-34.

[44] R.N. Cavalcanti, P.C. Veggi, M.A.A. Meireles, Supercritical fluid extraction with a modifier of antioxidant compounds from jabuticaba (Myrciaria cauliflora) byproducts: economic viability, Procedia Food Science, 1 (2011) 1672-1678.

[45] S. Rodrigues, F.A. Fernandes, E.S. de Brito, A.D. Sousa, N. Narain, Ultrasound extraction of phenolics and anthocyanins from jabuticaba peel, Industrial Crops and Products, 69 (2015) 400-407.

[46] D.T. Santos, P.C. Veggi, M.A.A. Meireles, Optimization and economic evaluation of pressurized liquid extraction of 
phenolic compounds from jabuticaba skins, Journal of Food Engineering, 108 (2012) 444-452.

[47] K.M. Khazaei, S. Jafari, M. Ghorbani, A.H. Kakhki, M. Sarfarazi, Optimization of anthocyanin extraction from saffron petals with response surface methodology, Food Analytical Methods, 9 (2016) 1993-2001.

[48] K. Ghafoor, J. Park, Y.-H. Choi, Optimization of supercritical fluid extraction of bioactive compounds from grape (Vitis labrusca B.) peel by using response surface methodology, Innovative Food Science \& Emerging Technologies, 11 (2010) 485-490.

[49] G. Cardoso-Ugarte, M. Sosa-Morales, T. Ballard, A. Liceaga, M. San Martín-González, Microwave-assisted extraction of betalains from red beet (Beta vulgaris), LWT-Food Science and Technology, 59 (2014) 276-282.

[50] P. Vazquez-Roig, Y. Picó, Pressurized liquid extraction of organic contaminants in environmental and food samples, TrAC Trends in Analytical Chemistry, 71 (2015) 55-64.

[51] K. Sharif, M. Rahman, J. Azmir, A. Mohamed, M. Jahurul, F. Sahena, I. Zaidul, Experimental design of supercritical fluid extraction-A review, Journal of Food Engineering, 124 (2014) $105-116$.

[52] M. Herrero, J.A. Mendiola, A. Cifuentes, E. Ibáñez, Supercritical fluid extraction: recent advances and applications, Journal of Chromatography a, 1217 (2010) 2495-2511.

[53] C.M. Renard, Extraction of bioactives from fruit and vegetables: State of the art and perspectives, LWT, 93 (2018) 390-395.

[54] B.K. Tiwari, Ultrasound: A clean, green extraction technology, TrAC Trends in Analytical Chemistry, 71 (2015) 100-109.

[55] B. Chanukya, N.K. Rastogi, Ultrasound assisted forward osmosis concentration of fruit juice and natural colorant, Ultrasonics sonochemistry, 34 (2017) 426-435.

[56] E.K. Silva, M.T.M. Gomes, M.D. Hubinger, R.L. Cunha, M.A.A. Meireles, Ultrasound-assisted formation of annatto seed oil emulsions stabilized by biopolymers, Food Hydrocolloids, 47 (2015) 1-13.

[57] S. Adeel, M. Hussaan, F.-u. Rehman, N. Habib, M. Salman, S. Naz, N. Amin, N. Akhtar, Microwave-assisted sustainable dyeing of wool fabric using cochineal-based carminic acid as natural colorant, Journal of Natural Fibers, (2018) 1-9.

[58] K.K.H.Y. Ho, M.G. Ferruzzi, A.M. Liceaga, M.F. San Martín-González, Microwave-assisted extraction of lycopene in tomato peels: Effect of extraction conditions on all-trans and cis-isomer yields, LWT - Food Science and Technology, 62 (2015) 160-168.

[59] F.J. Barba, Z. Zhu, M. Koubaa, A.S. Sant'Ana, V. Orlien, Green alternative methods for the extraction of antioxidant bioactive compounds from winery wastes and by-products: a review, Trends in Food Science \& Technology, 49 (2016) 96-109.

[60] M.D. Luque de Castro, L.S. Castillo-Peinado, 3 Microwave-Assisted Extraction of Food Components, in: K. Knoerzer, P. Juliano, G. Smithers (Eds.) Innovative Food Processing Technologies, Woodhead Publishing, 2016, pp. $57-110$.

[61] S. Silva, E. Costa, C. Calhau, R. Morais, M. Pintado, Anthocyanin extraction from plant tissues: a review, Critical reviews in food science and nutrition, 57 (2017) 3072-3083.

[62] R. Romero-Díez, M. Matos, L. Rodrigues, M.R. Bronze, S. Rodríguez-Rojo, M.J. Cocero, A.A. Matias, Microwave and ultrasound pre-treatments to enhance anthocyanins extraction from different wine lees, Food chemistry, 272 (2019) 258-266.

[63] I. Elez Garofulić, V. Dragović-Uzelac, A. Režek Jambrak, M. Jukić, The effect of microwave assisted extraction on the isolation of anthocyanins and phenolic acids from sour cherry Marasca (Prunus cerasus var. Marasca), Journal of Food Engineering, 117 (2013) 437-442.

[64] A. Baiano, L. Bevilacqua, C. Terracone, F. Contò, M.A. Del Nobile, Single and interactive effects of process variables on microwave-assisted and conventional extractions of antioxidants from vegetable solid wastes, Journal of Food Engineering, 120 (2014) 135-145.

[65] B.E. Richter, B.A. Jones, J.L. Ezzell, N.L. Porter, N. Avdalovic, C. Pohl, Accelerated solvent extraction: a technique for sample preparation, Analytical Chemistry, 68 (1996) 1033-1039.

[66] R.L. Jackman, R.Y. Yada, M.A. Tung, R.A. Speers, Anthocyanins as food colorants - a review, Journal of food biochemistry, 11 (1987) 201-247.

[67] N. Chhikara, K. Kushwaha, P. Sharma, Y. Gat, A. Panghal, Bioactive compounds of beetroot and utilization in food processing industry: A critical review, Food chemistry, 272 (2018) 192-200.

[68] R. Ravanfar, T.A. Comunian, A. Abbaspourrad, Thermoresponsive, water-dispersible microcapsules with a lipid-polysaccharide shell to protect heat-sensitive colorants, Food Hydrocolloids, 81 (2018) 419-428.

[69] M.I. Khan, P.S. Harsha, A. Chauhan, S. Vijayendra, M. Asha, P. Giridhar, Betalains rich Rivina humilis L. berry extract as natural colorant in product (fruit spread and RTS beverage) development, Journal of food science and technology, 52 (2015) 1808-1813

[70] P. Anand, A.B. Kunnumakkara, R.A. Newman, B.B. Aggarwal, Bioavailability of curcumin: problems and promises, Molecular pharmaceutics, 4 (2007) 807-818.

[71] G.B. Celli, A. Ghanem, M.S.-L. Brooks, Bioactive Encapsulated Powders for Functional Foods-a Review of Methods and Current Limitations, Food and Bioprocess Technology, 8 (2015) 1825-1837.

[72] Q. Ye, N. Georges, C. Selomulya, Microencapsulation of active ingredients in functional foods: From research stage to commercial food products, Trends in Food Science \& Technology, 68 (2018) 167-197.

[73] R.E. Kopec, M.L. Failla, Recent advances in the bioaccessibility and bioavailability of carotenoids and effects of other dietary lipophiles, Journal of Food Composition and Analysis, 68 (2018) 16-30.

[74] L.C. Price, R. Buescher, Decomposition of Turmeric curcuminoids as affected by ligth, solvent and oxygen Journal of food biochemistry, 20 (1996) 125-133. 
[75] E.K. Silva, G.L. Zabot, A.M. MA, Ultrasound-assisted encapsulation of annatto seed oil: Retention and release of a bioactive compound with functional activities, Food research international, 78 (2015) 159-168.

[76] E.K. Silva, V.M. Azevedo, R.L. Cunha, M.D. Hubinger, M.A.A. Meireles, Ultrasound-assisted encapsulation of annatto seed oil: Whey protein isolate versus modified starch, Food Hydrocolloids, 56 (2016) 71-83.

[77] S. Ray, U. Raychaudhuri, R. Chakraborty, An overview of encapsulation of active compounds used in food products by drying technology, Food Bioscience, 13 (2016) 76-83.

[78] A. Arango-Ruiz, A. Martin, M.J. Cosero, C. Jimenez, J. Londono, Encapsulation of curcumin using supercritical antisolvent (SAS) technology to improve its stability and solubility in water, Food chemistry, 258 (2018) 156-163.

[79] D.S. Tupuna, K. Paese, S.S. Guterres, A. Jablonski, S.H. Flôres, A.d.O. Rios, Encapsulation efficiency and thermal stability of norbixin microencapsulated by spray-drying using different combinations of wall materials, Industrial Crops and Products, 111 (2018) 846-855.

[80] F. Temelli, Perspectives on the use of supercritical particle formation technologies for food ingredients, The Journal of Supercritical Fluids, 134 (2018) 244-251.

[81] D. Sanli, S. Bozbag, C. Erkey, Synthesis of nanostructured materials using supercritical CO2: Part I. Physical transformations, Journal of Materials Science, 47 (2012) 2995-3025.

[82] E. Reverchon, R. Adami, G. Caputo, I. De Marco, Spherical microparticles production by supercritical antisolvent precipitation: interpretation of results, The Journal of Supercritical Fluids, 47 (2008) 70-84.

[83] F. Kurniawansyah, R. Mammucari, N.R. Foster, Polymorphism of curcumin from dense gas antisolvent precipitation, Powder Technology, 305 (2017) 748-756.

[84] H.Y. Jin, M. Hemingway, F. Xia, S.N. Li, Y.P. Zhao, Production of $\beta$-carotene nanoparticles by the solution enhanced dispersion with enhanced mass transfer by ultrasound in supercritical CO2 (SEDS-EM), Industrial \& Engineering Chemistry Research, 50 (2011) 13475-13484.

[85] W.L. Priamo, A.M. de Cezaro, S.C. Benetti, J.V. Oliveira, S.R. Ferreira, In vitro release profiles of $\beta$-carotene encapsulated in PHBV by means of supercritical carbon dioxide micronization technique, The Journal of Supercritical Fluids, 56 (2011) 137-143.

[86] L. Zhao, F. Temelli, Preparation of anthocyanin-loaded liposomes using an improved supercritical carbon dioxide method, Innovative food science \& emerging technologies, 39 (2017) 119-128.

[87] A.P.D.F. Machado, M. Rueda, G.F. Barbero, Á. Martín, M.J. Cocero, J. Martínez, Co-precipitation of anthocyanins of the extract obtained from blackberry residues by pressurized antisolvent process, The Journal of Supercritical Fluids, 137 (2018) 81-92.

[88] J.F. Osorio-Tobón, P.I. Carvalho, M.A. Rostagno, A.J. Petenate, M.A.A. Meireles, Precipitation of curcuminoids from an ethanolic turmeric extract using a supercritical antisolvent process, The Journal of Supercritical Fluids, 108 (2016) 26-34.

[89] G.P. Blanch, M.L. Ruiz del Castillo, M. del Mar Caja, M. Pérez-Méndez, S. Sánchez-Cortés, Stabilization of all-trans-lycopene from tomato by encapsulation using cyclodextrins, Food chemistry, 105 (2007) 1335-1341.

[90] A. Tabernero, E.M.M. del Valle, M.A. Galán, Supercritical fluids for pharmaceutical particle engineering: Methods, basic fundamentals and modelling, Chemical Engineering and Processing: Process Intensification, 60 (2012) 9-25.

[91] E. Reverchon, Supercritical antisolvent precipitation of micro-and nano-particles, The journal of supercritical fluids, 15 (1999) 1-21.

[92] M.J. Cocero, Á. Martín, F. Mattea, S. Varona, Encapsulation and co-precipitation processes with supercritical fluids: Fundamentals and applications, The Journal of Supercritical Fluids, 47 (2009) 546-555. 